\title{
IDENTIFYING CRITICAL ELEMENTS OF ROAD INFRASTRUCTURE USING CASCADING IMPACT ASSESSMENT
}

\author{
David REHAK ${ }^{1^{*}}$, David PATRMAN ${ }^{2}$, Veronika BRABCOVÁ ${ }^{3}$, Zdeněk DVOŘÁK ${ }^{4}$ \\ 1,2,3 Faculty of Safety Engineering, Technical University of Ostrava, Czech Republic \\ ${ }^{4}$ Faculty of Security Engineering, University of Žilina, Slovak Republic
}

Received 3 October 2019; revised 16 November 2019; accepted 9 January 2020;

first published online 4 May 2020

\begin{abstract}
Road transport is a key means of transporting people and cargo on land. Its particular advantages are speed and operability, which are balanced, however, by dependence on road infrastructure. Road infrastructure reliability is an important factor in its functioning. If some elements of road infrastructure are disrupted or fail, the function of dependent infrastructures, such as the integrated rescue system or industry, are also impaired and may fail. These important elements of road infrastructure should be identified as critical and be given greater attention when identifying weaknesses and implementing subsequent security measures. This article introduces the Identifying Critical Elements of Road Infrastructure (ICERI) method, which was designed to make use of Cascading Impact Assessments (CIA). The use of CIA allows critical elements to be identified through impact escalation analysis. These impacts can therefore be monitored not only in road transport infrastructure but also across the entire critical infrastructure system.
\end{abstract}

Keywords: critical infrastructure, road infrastructure, critical elements, cascade effects, identification, ICERI method.

\section{Introduction}

The importance of transport in the modern world is reflected by its inclusion in 2008 into the European critical infrastructure sectors (EC 2008), under which the European Council specified four sub-sectors: road transport, rail transport, air transport and waterway transport (includes inland waterways transport and ocean and shortsea shipping and ports). Road transport currently has an irreplaceable role in the European transportation network. This fact is supported by a significantly greater rate of motorization and in the growth of motorway network density in 2006-2016, which took place in virtually all European countries (UNECE 2018). Another statistic showing the increasingly important role of road transport is the ongoing growth of cabotage road transport across Europe in 2013-2017 (Eurostat 2018).

The foundation of a functioning transport system is high-quality and highly reliable infrastructure. This transport infrastructure comprises elements (EC 2006) so significant that their failure would cause traffic collapse (Jenelius 2007). These elements are referred to as critical, and their importance in the transport infrastructure system can be derived from their level of impact on depend- ent elements (Rinaldi et al. 2001). Indeed, in the context of this article, criticality is understood as the relative importance and significance of a given element that also expresses the vulnerability of that element and the potential adverse effects of its failure with regard to the links in that system. Assessment of the criticality of elements in terms of safety (e.g., Ambros et al. 2019) is not the subject of this article.

Critical elements require greater attention, which means they must be identified early and have their resilience levels analysed (e.g., Rehak et al. 2019a; Nan, Sansavini 2017; Bertocchi et al. 2016). In the context of assessing current risks (e.g., Giannopoulos et al. 2012), adequate security measures can subsequently be adopted to enhance their protection (e.g., Štoller et al. 2018; Klein, Hutter 2017; Labaka et al. 2015; Hromada, Lukas 2012).

Current studies and publications dealing with identifying critical elements in road transport can be categorized into two groups. The first group represents universal methods applicable to all areas of transport, namely road, rail, air, ship (e.g., Dvořák et al. 2017). The second group comprises specific methods that focus exclusively on road

*Corresponding author. E-mail: david.rehak@vsb.cz 
transport. This group most often identifies critical links or nodes in the road network. To identify these critical elements, a full network scan method is most often recommended (e.g., Jenelius et al. 2006; Taylor et al. 2006). This method is based on a systematic analysis of the impact on accessibility to network sections in the event of their closure. However, in cases of very large road networks, this involves a complicated and lengthy mathematical calculation (e.g., large cities or agglomerations). For this reason, a full network scan approach may in some cases appear impractical (Chen et al. 2012).

Because of these computational demands, an alternative method was developed. This method uses a partial network scan algorithm based on analysing the length and number of replacement routes for given sections (Yang et al. 2016). Another view offers a method based on the link redundancy of a sub-network, namely the availability of replacement routes (Yu et al. 2014). This method uses two indexes to assess criticality: the link redundancy index and link criticality index. The authors mention that this method is much more effective in identifying the same critical elements than the full network scan method mentioned above.

Another method is to identify critical elements based on the macroscopic fundamental diagram theory (Dong et al. 2017). The authors describe this approach as the relationship between traffic volume and the density of a road network and the relationship between area-weighted volume and the total traffic amount in a network. Yet another method is based on the Network Robustness Index (Scott et al. 2006), which makes it possible to determine the value of individual segments or links in the entire motorway system while identifying critical links requiring improvement. Another possible method is assessing the criticality of elements through their vulnerability (Oliveira $e t a l$. 2014; Taylor, D’Este 2007) or significance (Rupi et al. 2015).

This review revealed that no specific method for identifying the critical elements of all linear, point and areal topological structures is currently available (Slivkova et al. 2018). One of the main, obvious reasons is the inability to evaluate the correlation between elements with different topologies. It is also evident that none of the specific methods allows a systemic assessment of the intensity of spreading impact. When the criticality of elements and their significance and links to dependent elements are evaluated in the scope of evaluating the territorial unit, an analysis of spreading impact could help draw attention to their significance and links to these dependent elements.

A potential solution can be found in implementing the results of cascade impact assessment (Rehak et al. 2018). Based on the above, the article introduces the Identifying Critical Elements of Road Infrastructure (ICERI) method, which is suitable for ICERI using Cascading Impact Assessment (CIA). The use of CIA allows critical elements to be identified using an impact spread analysis. These impacts can be monitored not only in the sub-sector of road transport but also across the entire critical infrastructure system.

\section{Infrastructure elements of road transport}

Road infrastructure consists mainly of roads of different class (motorways, expressways, roads, local roads). According to the Commission Regulation (EC 2006), other elements of road infrastructure are land, road bodies (furrows, embankments, drainage equipment), civil engineering (bridges, underpasses, overpasses, tunnels, avalanche and falling rock protective structures, snow barriers), level crossings, traffic signs and signalling, telecommunications equipment and lighting equipment (Leitner et al. 2019).

Depending on their importance, some elements are indicated as critical infrastructure elements and can be classified at European or national levels. How European critical infrastructure elements are designated is defined by the Council Directive (EC 2008). Elements that can be categorized as such fall into two sub-sectors: energy and transport. Designating national elements of critical infrastructure, however, is dependent on the individual country. The established criteria that elements must meet to be designated as elements of national critical infrastructure often vary widely between countries, resulting in ambiguous classification (Slivková et al. 2015). Some member states also often illogically assign the above-mentioned criteria. The level of significance of an element in a critical infrastructure system may also not be appropriately considered when it is defined. In practice, situations then arise under specific criteria where no element or only few elements can be identified as elements of critical infrastructure.

\subsection{Links between elements of road infrastructure}

When assessing the importance of individual elements, their significance and correlation in the critical infrastructure system must be considered. The correlation of elements, meanwhile, is determined by the links between them. The work of authors Rinaldi et al. (2001) is pivotal in evaluating the links between elements. This research demonstrated the interdependence of critical infrastructure elements and defined four types of link:

- physical (the type of interdependency when each of two infrastructures are dependent on the material output(s) of the other);

- cyber (the type of interdependency when an infrastructure is dependent on the information transmitted through the information infrastructure);

- geographic (the type of interdependency when local environmental events can create state changes in all infrastructures);

- logical (the type of interdependency when the state of each of two infrastructures depends on the state of the other through a mechanism that is not a physical, cyber or geographic connection).

These types of links can be further classified according to their state, which can have three forms: dependence, interdependence and influence (Rehak, Novotny 2016). Dependence is defined as a link or connection between two infrastructures through which the state of one infra- 
structure is affected by or correlates with the state of the other. Interdependence refers to a two-way relationship between two infrastructures that affects or correlates with the state of each infrastructure. Generally speaking, two infrastructures are interdependent if each is dependent on the other. By contrast, influence is characteristic that has no need to identify a relationship for it. An example may be a situation in which the assessed element $B$ is not dependent on the function of element $\mathrm{A}$, but may be positively or negatively influenced by element A.

Another possible method of classifying links is represented by their division according to the level of the link, specifically (Rehak et al. 2016):

- systemic level - this is the type of link represented by the dependence or influence of sectors across the entire critical infrastructure system (e.g., the dependency of the integrated rescue system on road infrastructure);

- sectoral level - this is the type of link represented by the dependence or influence of sub-sectors within a given critical infrastructure sector (e.g., the impact of disrupted road infrastructure on rail transport);

- sub-sectoral level - this is the type of link represented by the dependence or influence of individual elements within a given sub-sector (e.g., the dependence of a motorway on a motorway bridge or the effect of motorway failure on surrounding roads).

\subsection{Classification of infrastructure elements according to their topological structure}

An important factor in identifying critical elements of road transport is their topological structure. From the perspective of topology, these elements can be classified similarly to railway infrastructure into three basic groups: (1) linear, (2) point, (3) areal elements (Slivkova et al. 2018).

The first group represents linear or line elements, which in the case of road infrastructure are the linear elements of motorways and roads of different categories. Their importance depends on the performance they provide, such as the capacity and intensity of traffic in a given area (Patrman et al. 2019) and the levels of the links to dependent or influenced elements.

The second group is point elements, which in the case of road infrastructure are represented by, for example, bridges, tunnels or junctions. The performance of these elements is usually defined by traffic permeability (Patrman et al. 2019), whereas dependent or influenced elements are road sections (i.e., linear elements) connected to these point elements.

The third group comprises areal elements. In the case of road infrastructure, these are, for example, bus stations. The performance of these elements is defined by the number of vehicles passing per unit of time. Identifying dependent or influenced elements in this group in road infrastructure is already no longer possible. The impacts are already affecting commuters.

\section{Spread and assessment of cascading impacts in a critical infrastructure system}

The core of impacts that spread through a critical infrastructure system is the failures occurring from the adverse effects of safety risks (i.e., the causes of disruption to or failure of critical infrastructure elements). These risks can be of an external or internal nature. The impacts can then directly affect society (direct impacts), spread across critical infrastructure and create additional disruptions that have additional impacts (cascading impacts). As a result, the cascading impacts can affect a single element simultaneously (synergistic effects) (Rehak et al. 2018). A graphic representation of how these impacts spread in a critical infrastructure system is shown in Figure 1.

Cascading effects are the effects caused by disruption to or the failure of critical infrastructure elements. These then further spread across the critical infrastructure and cause dependent elements to fail, which results in other impacts escalating (Rehak et al. 2018). An example might be the effect of a safety risk $R_{2}$ (e.g., terrorist attack) in sector $S_{2}$ (e.g., the electric power industry). As a result of this adverse effect, the functionality of $S_{2}$ sector is disrupted, which then cascades into the dependent $S_{3}$ sector (e.g., transport sector). Disrupting both sectors results in a cascading impact on society as a whole. This specific situation represents the spread of cascading effects of common-cause failures, i.e. when two or more infrastructure networks are disrupted simultaneously (Kotzanikolaou et al. 2013).
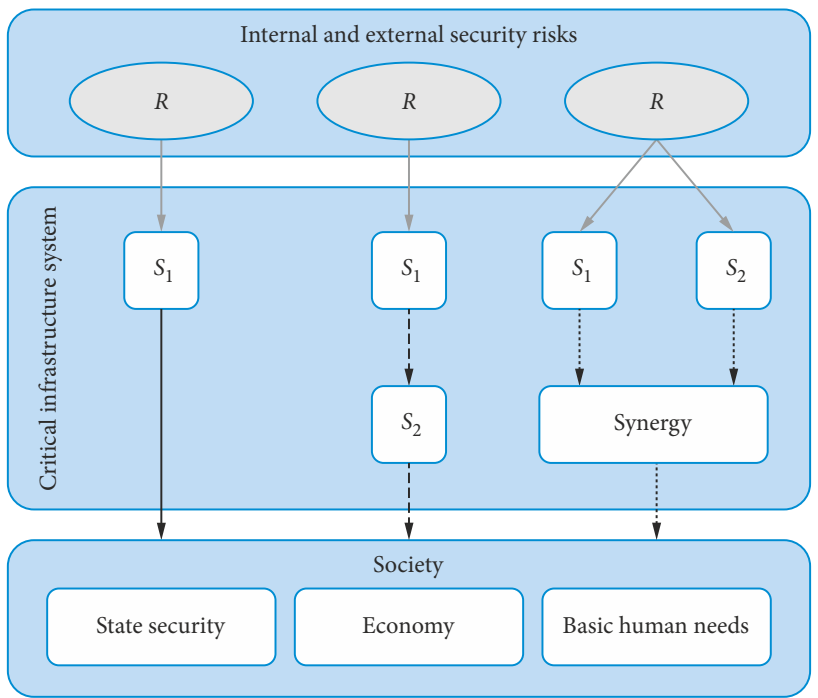
security risks

critical infrastructure sectors

$\longrightarrow$ cause of disruption to or failure of the critical infrastructure

$\longrightarrow$ direct impact

$\rightarrow$ cascading impact

........... - synergistic impact

Figure 1. Representation of how effects spread in a critical infrastructure system (Rehak et al. 2018) 
CIA is an important tool in examining critical infrastructure. Without predictive modelling tools, the potential impacts of disruption to or failure of critical infrastructure elements cannot be identified promptly. The starting point of cascade impact assessment is a detailed analysis of the system in which links between elements are assumed (Zimmerman, Restrepo 2009). Analysing these links and determining their intensity is then necessary.

Methods that assess cascading impacts in a critical infrastructure system primarily focus on the electricity sector, which was designated in the Presidential Policy Directive PPD-21 as a uniquely critical sector (The White House 2013). However, from the perspective of evaluation, these methods are applicable even to other technically oriented critical infrastructure sectors.

The first major study of the assessment of cascade effects in the context of power failure was conducted by Bie and Wang (2002). According to the authors, cascading failures in the power generation industry are usually caused by common mode failures such as connection failure, cabinet failure, etc. In their work, they published a five-part algorithm comprising failure analysis, network topology, network connectivity assessment, system status evaluation and index statistics.

Another area of importance is examining the probability of a cascading failure developing from an unforeseeable event with regard to network load (Liao et al. 2004). This approach is based on the phase transitions of the probability of cascading failures, verified experimentally using lower and higher resolution networks. Both types of network demonstrate phase transitions. The results of the experiment confirmed a variant where the cascade failure risk assessment is based on a search near the current operating point for the phase transition of the probability of cascading impacts.

The method to study cascading effects (Hassel et al. 2014) deals with the nature and processes of cascading impacts. The authors point out that understanding the processes of cascading impacts can help address and mitigate their effects. At the same time, they present a methodology designed to characterize and analyse these impacts. In the description, they draw on input data from the analyses of emergencies that have already happened in the past. They also examine the conditions that contribute to the deterioration of the extent of cascading impacts and to the conditions that reduce the effects of cascading impacts. The presented method is based on a conceptual model of cascading impacts, which comprises three basic steps. The first is identifying a disrupted (dependent) system, specifically whether this system is directly affected by the initiation event or is indirectly influenced through a link to the influencing system. The second step is describing the impacts on all other disrupted systems in order to understand how and to what extent a dependent system is influenced by an influencing system. The last step examines the impact system targeting all dependent systems affected by the initiation event.
In the following years, a comprehensive methodology based on reliability methods was introduced to automatically generate scenarios during critical infrastructure failures with subsequent cascading impacts (Gonzva et al. 2016). In their study, the authors presented existing methods for assessing interdependencies in the critical infrastructure system with a focus on assessing their reliability. In the case study, they assessed the cascading impacts between electricity and rail transport. This assessment was based on the use of the fault tree analysis (IEC 61025:2006) and failure mode and effects analysis (IEC 60812:2006) methods.

An appropriate method of assessing cascading impacts is an approach based on evaluating technical systems (Renger et al. 2017). System evaluation theory applies both systemic thinking and system theory. Using three steps, an evaluator can (1) define the system, (2) evaluate system efficiency, (3) evaluate system effectiveness. The authors also state that the effectiveness of a system depends on prompt, sufficiently frequent, specific, relevant and reliable sharing of information at and between sub-systems through feedback mechanisms, i.e., feedback in the context of the sub-system or between individual sub-systems.

Another possible view of the issue in question is offered in the research by Chen and Milanović (2017). The authors presented selected methods for modelling and simulations designed to analyse infrastructure interdependencies on models based on a factor or so-called agent. These are most often used because of the detailed depiction of system behaviour. In this model, the underlying element or agent is designed to provide a particular service and follows a series of "what if" rules and predefined attributes, making it possible to learn and respond accordingly.

Zuccaro et al. (2018) described the possibility of extraordinary events occurring to assessed elements in which multiple events may act simultaneously on one element. This phenomenon can significantly affect the spread of impacts by cascading effects. It also has to be carefully assessed in terms of emergency planning and management. The article discusses, from a theoretical point of view, the needs of modelling and the main issues for consideration when simulation tools are developed that aim to incorporate the analyses of cascading impacts and effectively support stakeholders in their preparations to solve and mitigate their consequences through planning at local, national and international levels. The aim of this model is to describe scenarios of spreading cascading impacts at different levels according to the availability of data for different categories of elements and models for different sources of risk.

The final current tool is the CIA method, which was developed to quantify the spread of cascading impacts in critical infrastructure system (Rehak et al. 2018). The basis of the evaluation process is formulating a static stochastic model of critical infrastructure elements and the depend- 
encies between them. This model is based on predicting the percentage of probability and the impact intensity. This method assesses all elements found in a selected area and evaluates their resilience (NIAC 2009) and links (Rinaldi et al. 2001). A structural map of the risk of the spread of cascading impacts can then be created. Evaluation of the risk of spreading cascading impacts is based on three limiting factors: (1) the intensity of the initiation threat (i.e., the drop in the level of service delivery from the previous sector), (2) the level of resilience of the dependent branches, (3) the intensity of the link between the evaluated branches.

\section{Method for ICERI}

Prudent identification of critical elements allows their resilience to be accordingly evaluated (e.g., Rehak et al. 2019a; Nan, Sansavini 2017; Bertocchi et al. 2016). Weaknesses can be identified and retroactively strengthened (e.g., Public Safety Canada 2018; Labaka et al. 2015). However, no suitable method for comprehensively identifying elements of all linear, point and areal topological structures is currently available (Slivkova et al. 2018). For this reason, the authors of the article propose the ICERI method, which was created specifically to identify critical elements of road infrastructure.

This method analyses the spread of impacts of potentially disrupted road infrastructure elements into dependent and influenced elements in the critical infrastructure system - both inside and outside the road transport sub-sector (e.g., impacts on electricity supply, healthcare facilities, integrated rescue systems, services and industry). This analysis is based on progressively evaluating the permeability of impacts between those elements whose dependence or influence has been identified (Rehak, Novotny 2016). The risk of spread of cascading impacts is then evaluated for these elements through the intensity of their links and the level of resilience in individual elements. This evaluation is performed from a macroscopic point of view, i.e., whole components of the system are examined, regardless of their detailed structure.

\subsection{Framework of the ICERI method}

ICERI using CIA is a relatively demanding process that requires a clearly defined framework. This framework consists of four basic areas: (1) elements of road infrastructure, (2) threats to road infrastructure elements, (3) dependent and influenced critical infrastructure elements, (4) methodology (Figure 2).

The basic areas of identifying critical elements are in the road infrastructure elements themselves. These can be classified into three basic groups according to their topological structure (Slivkova et al. 2018): (1) linear elements (e.g., motorways and roads), (2) point elements (e.g., bridges and tunnels), (3) area elements (e.g., bus stations). The criticality of these elements can be assessed not only in the road transport sub-sector but also in other relevant critical infrastructure sub-sectors (e.g., rail transport, the integrated rescue system, electricity supply).

An assessment of cascading impacts can only be conducted in relation to specific threats that may cause disruption to or the failure of road infrastructure elements (Patrman et al. 2019). To this end, eight basic threat groups were defined (Table 1) based on the peril event typology (IRDR 2014), which is used in large-scale event databases. From these events, only those threats in which the focus was primarily on infrastructure were selected.

As with classifying threats that affect road infrastructure elements, critical infrastructure elements dependent on or affected by road infrastructure elements also have to be classified. The first group comprises dependent elements that cannot function without road infrastructure elements. These elements occur not only in the transport sector (e.g., motorway dependency on a motorway bridge or tunnel) but also in other critical infrastructure sectors (e.g., the integrated rescue system's dependence on road infrastructure). The second group comprises elements whose function may be affected by the disruption to or failure of road transport elements. Again, these elements not only occur in the transport sector (e.g., the effect of motorway failure on the surrounding roads) but also in other sectors of critical infrastructure (e.g., the impact of road failures on healthcare services or electricity supply).

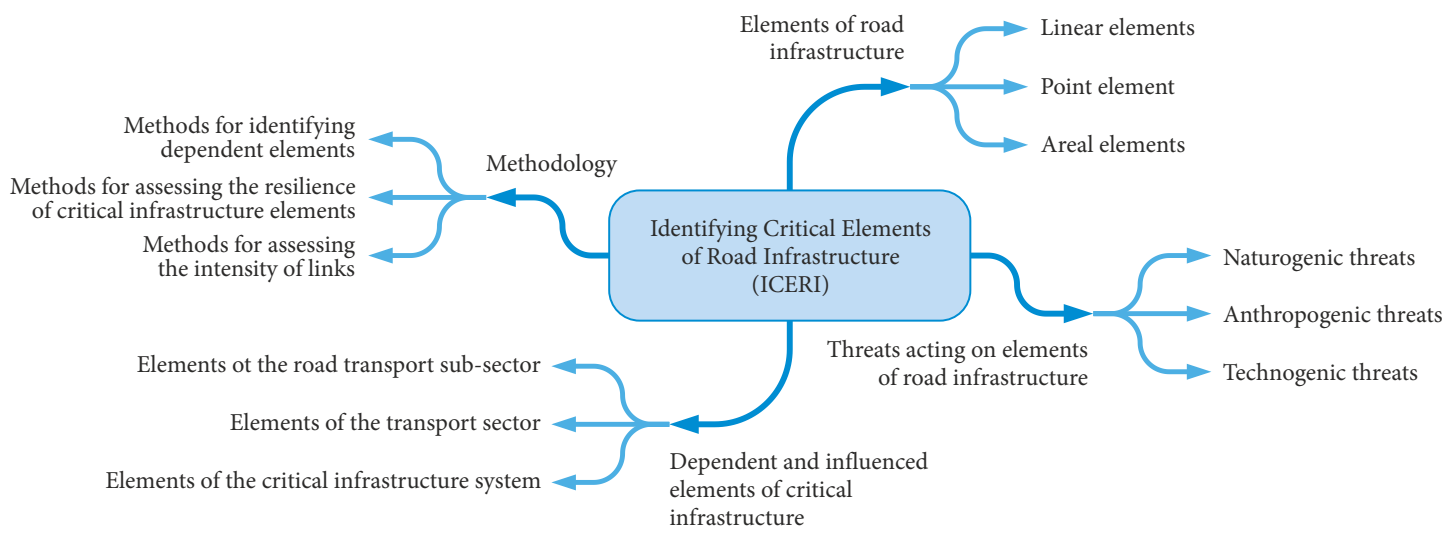

Figure 2. Framework of ICERI method 
Table 1. Classification of threats for assessing cascading effects in critical infrastructure system

\begin{tabular}{|c|c|c|c|}
\hline & Naturogenic threats & Technogenic threats & Anthropogenic threats \\
\hline Internal threats & - & procedural-technological & personnel \\
\hline \multirow{2}{*}{ External threats } & meteorological & cascading & cybernetic \\
\cline { 2 - 3 } & geological & & physical \\
\hline
\end{tabular}

The most important part of the framework of the ICERI method is the methodology forming the starting point for proposing the procedure of applying of this method. The methodology includes three important method groups, which are:

- methods suitable for identifying dependent and influenced elements, such as event tree analysis (IEC 62502:2010) or fault tree analysis (IEC 61025:2006),

- Critical Infrastructure Elements Resilience Assessment (CIERA) methods, such as the complex approach to assessing critical infrastructure elements (Rehak et al. 2019a) or the guidelines for critical infrastructure resilience evaluation (Bertocchi et al. 2016),

- methods of identifying and assessing the intensity of links (e.g., Seppänen et al. 2018; Gonzva et al. 2016; Min et al. 2007).

\subsection{Procedure of the ICERI method}

The above framework allows a procedure for ICERI to be defined. The structure of this procedure is based not only on general methods (e.g., IEC 31010:2019) but also on specific methods that assess critical elements in similar fields (e.g., Slivkova et al. 2018; Leitner et al. 2017; Pant et al. 2016). A procedure for applying the ICERI method was developed from these background materials and comprises eight consecutive steps (Figure 3).

The starting point in ICERI is delimiting the territory under evaluation (Step 1). Selecting the territory is not limited by anything, however, selecting smaller territorial units is recommended because of time constraints. If a larger territorial unit is evaluated, dividing it into several smaller parts is recommended. In this case, the occurrence of links between the elements of the individual parts must also be checked under the evaluation procedure.

This is followed by selecting the road infrastructure initiators (Step 2) located in the given territory. These are assessed against the specific, predicted threat (see the ICERI framework). Initiating elements are road infrastructure elements that are subsequently assessed for the risk of spreading cascading effects when the element is disrupted or fails. The elements with the highest level of risk are then designated as critical elements. These elements can be selected either according to documentation from the relevant authorities (e.g., Ministry of Transport of the Czech Republic) or through appropriate methods (e.g., Leitner et al. 2018; Dvořák et al. 2017), such as the Strengths, Weaknesses, Opportunities and Threats (SWOT) analysis method (Weihrich 1982). This method is recommended and may be used to identify weaknesses in elements and any external threats. Mainly, the highest priority elements of the "avoid" strategy should be evaluated.

The next step in applying the ICERI method is selecting elements that depend on initiating elements and any elements that may be affected by their disruption or failure (Step 3). Selecting elements is conducted in two stages. In the first stage, the sectors of interest and subsectors of critical infrastructure (e.g., electricity, medical facilities or integrated rescue system) are selected at the discretion of the evaluator. In the second stage, dependent or influenced critical infrastructure elements in these sectors and sub-sectors are selected. Selecting these elements is based on identifying links between these elements and the initiating elements, with an emphasis on dependence and influence (Rehak, Novotny 2016). Methods suitable for identifying and evaluating link intensities may be used for this purpose (e.g., Seppänen et al. 2018; Gonzva et al. 2016; Min et al. 2007).

After selecting the initiating, dependent and influenced elements, a structural map of cascading impacts can be created (Step 4). For this purpose, the event tree analysis (IEC 62502:2010) method is suitable. This method is used to analyse events that may lead to a potential accident. In the evaluation, the evaluator hypothesizes "what if", and in this manner searches for events that could potentially arise after an initiation event. From this evaluation stage, a structural map of the distribution of cascading effects between elements can be compiled and then quantified (Figure 4).

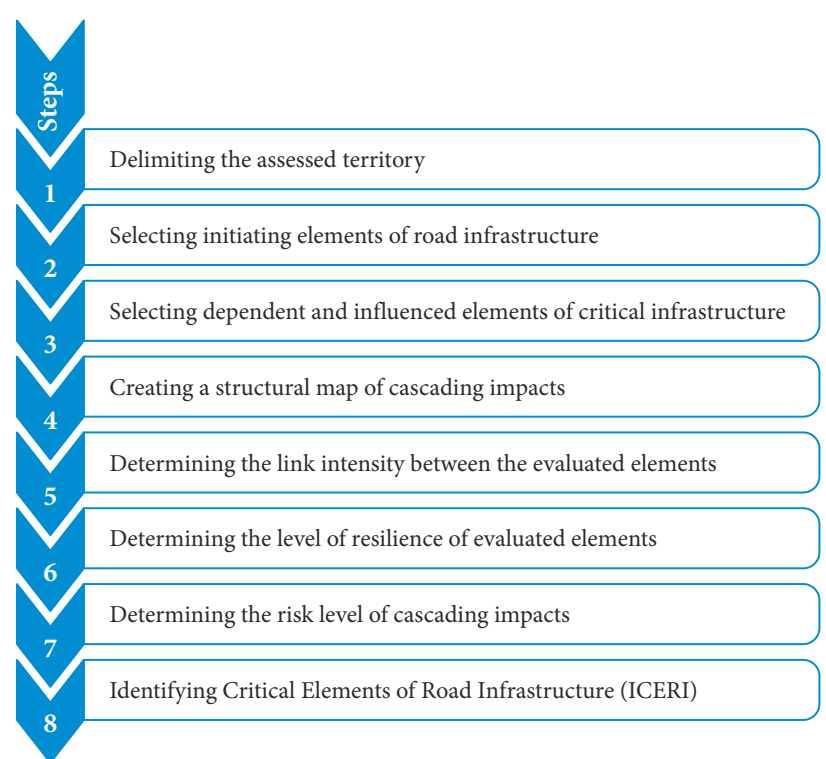

Figure 3. Procedure for applying the ICERI method 


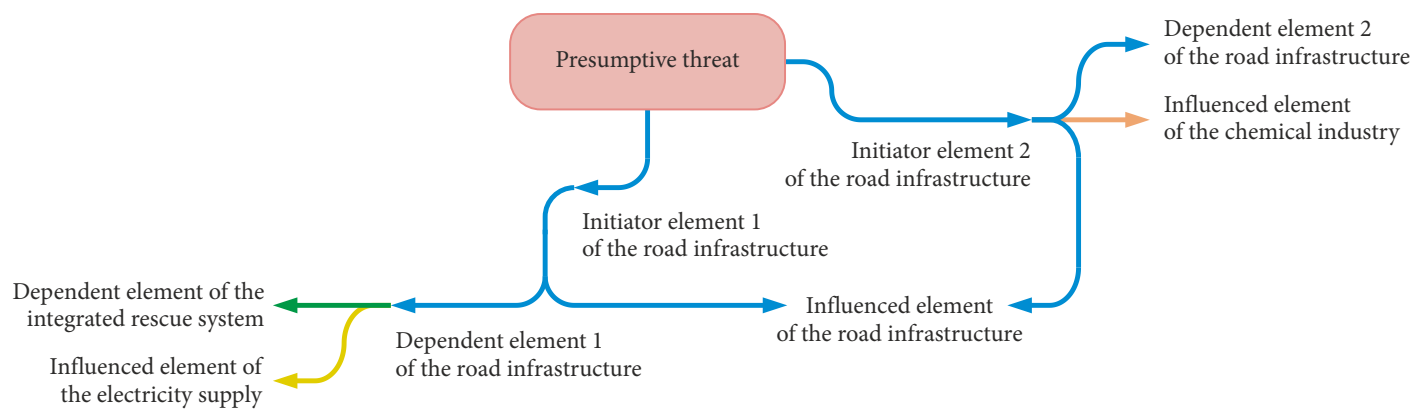

Figure 4. General depiction of a structural map of the spread of cascading impacts

For those elements between which a link has been identified, the intensity of this link is subsequently determined (Step 5). The intensity of the link is not only determined between the initiating element and its dependent elements in the road transport sector but also between dependent elements. The link intensity is measured according to the following criteria: (1) type of link, (2) state of link, (3) level of link, (4) substitution of link, (5) temporal character of the link, (6) structure of the link. The point score values of each criteria (i.e., 1 - criterion with a low-level link, 2 - criterion with a mid-level link, 3 criterion with a high-level link) were established using the pair comparison method (David 1988) and are presented in Table 2.

The criteria determining link intensity differ in their significance during evaluation. For this reason, normalized weights were defined for these criteria (Table 3). The

Table 2. Point values of the criteria determining link intensity

\begin{tabular}{|c|c|c|}
\hline \multicolumn{2}{|c|}{ Criteria determining link intensity $C_{i}$} & Point value \\
\hline \multirow{4}{*}{$\begin{array}{l}\text { Type of link } \\
\text { (Rinaldi et al. 2001) }\end{array}$} & physical link & 3 \\
\hline & geospatial link & 2 \\
\hline & cybernetic link & 2 \\
\hline & logical link & 1 \\
\hline \multirow{3}{*}{$\begin{array}{l}\text { State of link } \\
\text { (Rehak and Novotny } \\
\text { 2016) }\end{array}$} & mutual dependence & 3 \\
\hline & dependence & 2 \\
\hline & influence & 1 \\
\hline \multirow{3}{*}{$\begin{array}{l}\text { Level of link } \\
\text { (Rehak et al. 2016) }\end{array}$} & system link & 3 \\
\hline & sector link & 2 \\
\hline & sub-sector link & 1 \\
\hline \multirow{3}{*}{ Substitution of link } & no substitute link exists & 3 \\
\hline & $\begin{array}{l}\text { only one substitute link } \\
\text { exists }\end{array}$ & 2 \\
\hline & $\begin{array}{l}\text { two or more substitute } \\
\text { links exist }\end{array}$ & 1 \\
\hline \multirow{3}{*}{$\begin{array}{l}\text { Temporal } \\
\text { characteristic link }\end{array}$} & uninterrupted & 3 \\
\hline & periodic & 2 \\
\hline & stand-by & 1 \\
\hline \multirow{3}{*}{ Structure of link } & direct & 3 \\
\hline & indirect across one node & 2 \\
\hline & $\begin{array}{l}\text { indirect across two or } \\
\text { more nodes }\end{array}$ & 1 \\
\hline
\end{tabular}

normalized weights were defined using the pair comparison method (David 1988).

The final calculation of link intensity between elements is calculated from a weighted average according to Equation (1):

$$
I L=\sum_{i=1}^{n} C_{i} \cdot w_{i} \cdot \frac{100}{C_{i_{\max }}},
$$

where: $I L$ - intensity of the link between the evaluated elements [\%]; $C_{i}$ - point value of the $i$-th criteria; $n$ - number of criteria; $w_{i}$ - normalized weight of the $i$-th criteria [\%]; $C_{i_{\max }}$ - maximum point value of the $i$-th criteria.

The next step in the procedure of ICERI is determining the level of resilience of the elements under assessment (Step 6). The CIERA method (Rehak et al. 2019a) is recommended for this, as it permits the technical and organizational resilience of elements to be comprehensively assessed and their weaknesses identified in order to strengthen their resilience. The variables for resilience evaluation can be categorized into three groups according to the resilience determining components: robustness, recoverability and adaptability (NIAC 2009). An overview of these variables is presented in Table 4.

The point values of individual criteria and the process of assigning them are described in detail in the CIERA method (Rehak et al. 2019a). The final calculation of resilience level of the elements is calculated according to Equation (2):

$$
R E=\frac{1}{n} \cdot \sum_{j=1}^{n} K_{j}=\frac{1}{n} \cdot \sum_{j=1}^{n} \sum_{k=1}^{m} V_{k} \cdot w_{k},
$$

where: $R E$ - critical infrastructure element resilience [\%]; $K_{j}-j$-th critical infrastructure element resilience component [\%]; $n$ - total number of resilience determining components; $V_{k}$ - the $k$-th critical infrastructure element resilience variable [\%]; $w_{k}-k$-th normalized weight of the $k$-th variable resilience of the critical infrastructure element $[\langle 0 ; 1\rangle] ; m$ - total number of variables in the $j$-th component.

From the link intensity assessment and element resilience levels, the risk level of the spread of cascading impacts can then be determined (Step 7). This risk is always assessed separately in each pair of elements. The assessment's starting point is the general relationship where the 
Table 3. Normalized weights of criteria determining link intensity

\begin{tabular}{|c|c|c|c|c|c|c|c|}
\hline Criteria & $\begin{array}{c}\text { Type } \\
\text { of link }\end{array}$ & $\begin{array}{c}\text { State } \\
\text { of link }\end{array}$ & $\begin{array}{c}\text { Level } \\
\text { of link }\end{array}$ & $\begin{array}{c}\text { Substitution } \\
\text { of link }\end{array}$ & $\begin{array}{c}\text { Temporal character } \\
\text { of link }\end{array}$ & $\begin{array}{c}\text { Structure } \\
\text { of link }\end{array}$ & $\begin{array}{c}\sum \\
\text { Weight coefficients }\end{array}$ \\
\hline
\end{tabular}

Table 4. Variables determining the resilience of critical infrastructure elements (Rehak et al. 2019a)

\begin{tabular}{|c|c|}
\hline $\begin{array}{l}\text { Resilience components } \\
\text { of critical infrastructure } \\
\text { elements } K_{i}\end{array}$ & $\begin{array}{l}\text { Variables for assessing } \\
\text { resilience } V_{j}\end{array}$ \\
\hline \multirow{5}{*}{ Robustness } & crisis preparedness \\
\hline & redundancy \\
\hline & detection ability \\
\hline & responsiveness \\
\hline & physical resilience \\
\hline \multirow{4}{*}{ Recoverability } & material resources \\
\hline & financial resources \\
\hline & human resources \\
\hline & recovery process \\
\hline \multirow{3}{*}{ Adaptability } & risk management \\
\hline & innovation processes \\
\hline & $\begin{array}{l}\text { educational and development } \\
\text { processes }\end{array}$ \\
\hline
\end{tabular}

risk is expressed by a combination of the probability of occurrence of an undesirable event and its impact level (IEC 31010:2019). The probability of occurrence of cascading impacts, in this case, is determined by the link intensity $I L$. The cascading impact level is determined by the resilience of the evaluated elements $R E$. Higher resilience means adverse impacts are minimized because the vulnerability of these elements, which facilitates the spread of cascading impacts, is also minimized.

From the above, Equation (3) was derived to calculate the risk of a cascading impact spreading during disruption to or failure of road infrastructure elements:

$$
R=\sqrt[3]{V_{I E} \cdot V_{D E} \cdot I L}=\sqrt[3]{\left(1-R E_{I E}\right) \cdot\left(1-R E_{D E}\right) \cdot I L},
$$

where: $R$ - level of risk of a spreading cascading impact [\%]; $V_{I E}$ - vulnerability of the influencing element [\%]; $V_{D E}-$ vulnerability of the dependent element [\%]; $R E_{I E}$ - level of resilience of the influencing element [\%]; $R E_{D E}$ - level of resilience of the dependent element [\%]; IL - link intensity between the influencing and dependent element [\%].

The final step in the applying the ICERI method is identifying the critical elements of road infrastructure (Step 8). This is done using the results from the risk level assessment of cascading effects spreading between elements. These values are included in the structural map and then compared with reference values in order to categorize the level of spread of cascading impacts (Table 5).

The categorization of cascading effect levels and reference values is philosophically based on the failure mode, effects and criticality analysis (IEC 60812:2006). This method uses multiple variables to determine risk level and is based on variations in extreme values when evaluating states. Individual levels of criticality that factor in extreme value variation in the four-stage evaluation scale were determined in a manner similar to the method for assessing the criticality of railway infrastructure elements (Slivková 2018):

$$
\begin{aligned}
& -1,1,1,4=>\varnothing 1.75=>43.7 \% ; \\
& -1,1,4,4=>\varnothing 2.50=>62.5 \% ; \\
& -1,4,4,4=>\varnothing 3.25=>81.3 \% ; \\
& -4,4,4,4=>\varnothing 4.00=>100 \% .
\end{aligned}
$$

The final identification of critical elements of road infrastructure is achieved using the reference values for categorizing the level of spread of cascading impacts (Table 5). Elements demonstrating a critical risk level (i.e., Category I) between each other are subsequently designated as critical. Weaknesses should be identified in these elements and adequate safety measures then introduced in order to reduce link intensity and increase resilience (e.g., Štoller et al. 2018; Klein, Hutter 2017; Labaka et al. 2015; Hromada, Lukas 2012). Attention should also be given to elements demonstrating a high level of risk (i.e., Category II) between each other. In all other elements, significant proliferation of cascading impacts is not foreseen.

Table 5. Reference values for categorizing the level of spread of cascading impacts

\begin{tabular}{|l|l|l|}
\hline Interval & $\begin{array}{l}\text { Risk level of } \\
\text { spreading }\end{array}$ & \multicolumn{1}{|c|}{ Description } \\
\hline$(81 ; 100\rangle$ & Category I & $\begin{array}{l}\text { Critical risk level of the spread } \\
\text { of cascading impacts. } \\
\text { The result of such cascading } \\
\text { impacts may be the failure } \\
\text { of a dependent element }\end{array}$ \\
\hline$(62 ; 81\rangle$ & $\begin{array}{l}\text { High-risk level of the spread } \\
\text { of cascading impacts. } \\
\text { The result of such cascading } \\
\text { impacts may be significant } \\
\text { disruption to the functioning } \\
\text { of a dependent element }\end{array}$ \\
\hline$\langle 43 ; 62\rangle$ & $\begin{array}{l}\text { Acceptable risk level of the spread } \\
\text { of cascading impacts. } \\
\text { The result of such cascading } \\
\text { impacts may be partial disruption } \\
\text { to or limited functioning } \\
\text { of a dependent element }\end{array}$ \\
\hline$\langle 0 ; 43\rangle$ & $\begin{array}{l}\text { Low risk level of the spread } \\
\text { of cascading impacts. } \\
\text { This type of cascading impact } \\
\text { will not result in disruption to or } \\
\text { limited functioning } \\
\text { of a dependent element }\end{array}$ \\
\hline
\end{tabular}




\section{Case studies in applying the ICERI method}

The practical application of the ICERI method is presented as a case study to demonstrate the sequential evaluation of selected elements in eight consecutive steps (see below). The results obtained were subsequently discussed with stakeholders (i.e., Ministry of Transport of the Czech Republic, Czech Road and Motorway Directorate, Czech Railway and Traffic Route Administration, Regional Authority of the Moravian-Silesian Region, Emergency Medical Service of the Moravian-Silesian Region). The authenticity and predictive value of the results were confirmed.

Step 1: Delimiting the assessed territory. The starting point in ICERI is delimiting the territory under assessment. In order to test the ICERI method, the south-western part of the city of Ostrava was selected. A significant number of important elements of transport infrastructure are found in this city. Ostrava is located in the northeastern part of the Czech Republic and is an important road and rail transport hub to Slovakia and Poland.

Step 2: Selecting initiating elements of road infrastructure. The next step involved selecting the road infrastructure initiators located in the given territory. These were assessed against the specific, predicted threat (see ICERI framework). Because of the case study's scale, only one road infrastructure element was selected, namely the interchange of the D1 Motorway and Expressway 11 (Figure 5). This initiator element was selected using the assessment of critical infrastructure elements in transport method (Dvořák et al. 2017). The potential risk of this element collapsing due to the use of inappropriate background materials (RSD 2012) was considered. For this reason, the initiator was evaluated in terms of the risk created by poor technical condition.

Step 3: Selecting dependent and influenced elements of critical infrastructure. The next step in applying the ICERI method was selecting elements that may be ad- versely affected by disruption to or failure of the initiator element. Selecting these elements was conducted in two stages. In the first stage, the relevant critical infrastructure sub-sectors were selected, specifically road transport, rail transport and the integrated rescue system. In the second stage, the dependent and influenced elements of critical infrastructure in these sub-sectors were selected. These elements were identified from the links between these elements and the initiating element, with an emphasis on dependence and influence (Rehak, Novotny 2016). From this, a total of four elements were selected, which are shown in Figure 5.

Two dependent elements and two influenced elements were identified from the above map background. Expressway 11 and the integrated rescue system (specifically the emergency medical services) are elements dependent on the flyover intersection. The expressway facilitates transportation of patients from the Ostrava-Jih and Zábřeh districts to the hospital in Poruba (see top left). If the functioning of the flyover intersection fails (in the context of the selected threat, this would be the structure collapsing), traffic on the D1 Motorway and the high-speed railway corridor would be affected.

Step 4: Creating a structural map of cascading impacts. Based on the selected initiator and dependent and influenced elements, a structural map of the cascading impacts was created (Figure 6). For this purpose, the event tree analysis method (IEC 62502:2010) was used in order to analyse events that may lead to a potential accident.

Step 5: Determining the link intensity between the evaluated elements. The intensity of the links between elements sharing a link was then measured. Intensity was evaluated according to the determining criteria (Table 2) and then calculated according to Equation (1). The resulting values of link intensity between individual correlated elements are presented in Table 6.

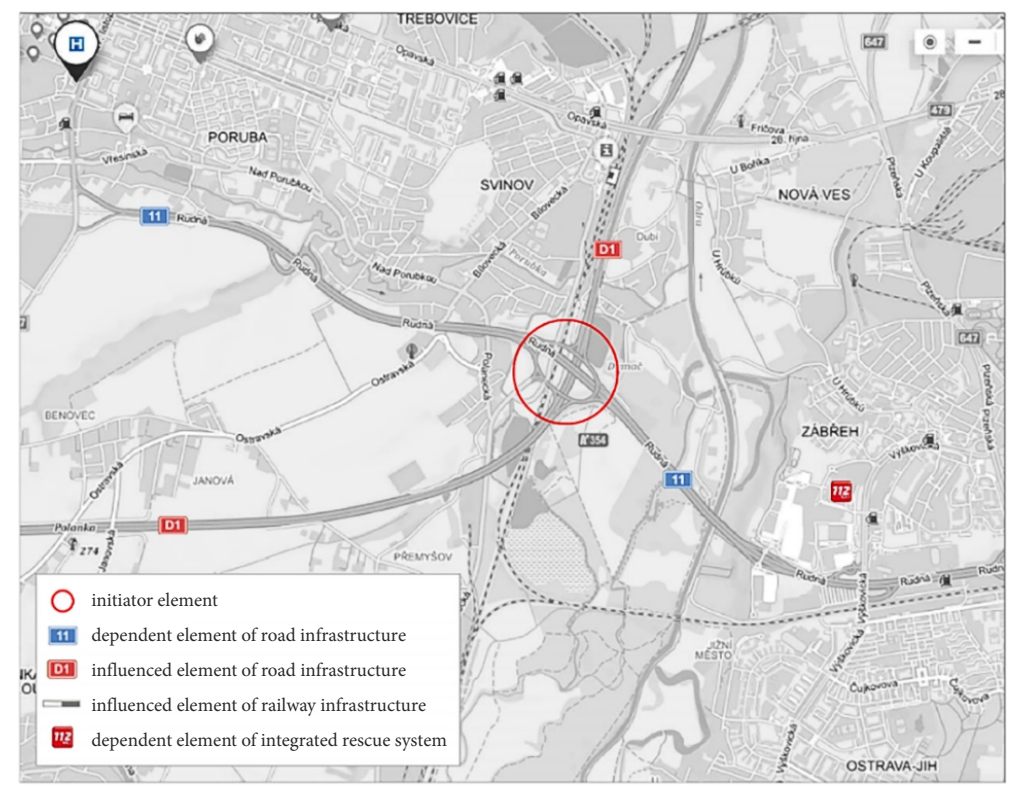

Figure 5. The selected elements plotted on a map background 


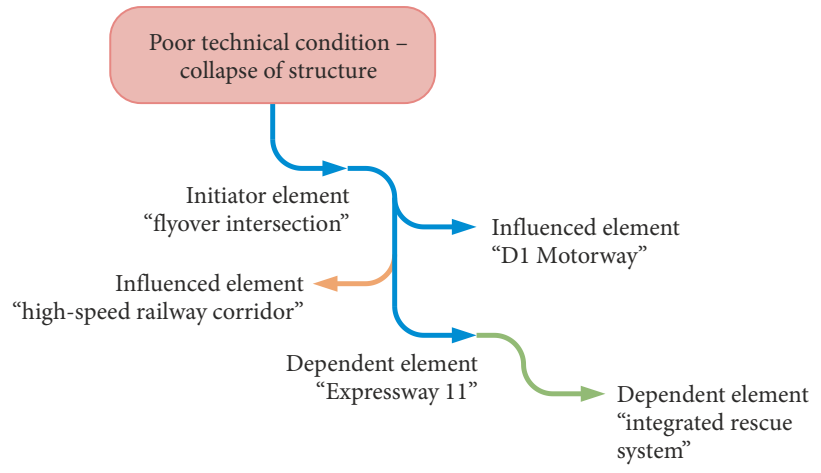

Figure 6. Structural map of the spread of cascading impacts in the event of a flyover intersection collapse

Step 6: Determining the level of resilience of evaluated elements. The next step in the process of ICERI was determining the level of resilience of the elements under assessment. For this purpose, the CIERA method (Rehak et al. 2019a) was used. This method permits the technical and organizational resilience of the elements to be comprehensively assessed and their weaknesses identified in order to strengthen their resilience. The level of resilience was assessed according to the determining criteria (Table 4) and then calculated according to Equation (2). The resulting resilience values of the individual elements are presented in Table 7.

Step 7: Determining the risk level of cascading impacts. From the link intensity assessment and element resilience levels, the risk level of the spread of cascading impacts can then be determined. This risk is always assessed separately in each pair of elements according to Equation (3). The resulting values are presented in Table 8.

Step 8: ICERI. The final step in the applying the ICERI method is identifying the critical elements of road in-
Table 6. Calculated link intensity between the evaluated elements

\begin{tabular}{|l|l|c|}
\hline Link level & \multicolumn{1}{|c|}{ Evaluated Links } & Link intensity [\%] \\
\hline \multirow{4}{*}{$\begin{array}{l}\text { Primary } \\
\text { links }\end{array}$} & $\begin{array}{l}\text { dependence of Expressway 11 } \\
\text { on the flyover intersection }\end{array}$ & $\begin{array}{l}\text { influence of the flyover } \\
\text { intersection on the } \\
\text { D1 Motorway }\end{array}$ \\
\cline { 2 - 3 } & $\begin{array}{l}\text { Influence of the flyover } \\
\text { intersections on the high- } \\
\text { speed railway corridor }\end{array}$ & 63 \\
\hline $\begin{array}{l}\text { Secondary } \\
\text { links }\end{array}$ & $\begin{array}{l}\text { effect of Expressway 11 on } \\
\text { the integrated rescue system }\end{array}$ & 60 \\
\hline
\end{tabular}

frastructure. This is done using the results from the risk level assessment of cascading effects spreading between elements (Table 8). These values were then compared with reference values in order to categorize the level of spread of cascading impacts (Table 5).

The results of the evaluation showed that the greatest risk of cascading impacts spreading was between the flyover intersection and Expressway 11. The risk value reached $63 \%$, meaning the cascading impacts had a high level of risk of spreading (i.e., Category II). Its reason was the dependence of Expressway 11 on the flyover intersection and the low level of resilience in both elements. By contrast, the lowest risk of the cascading impacts spreading was between Expressway 11 and the Integrated Rescue System, where the risk value was $41 \%$ (i.e., Category IV). Its reason was the low dependence of the Integrated Rescue System on the expressway (this section of road section has several detour options) and a high resilience in the Integrated Rescue System.

Table 7. Calculated level of resilience of evaluated elements

\begin{tabular}{|l|c|c|c|c|}
\hline \multicolumn{1}{|c|}{ Evaluated elements } & Robustness [\%] & Recoverability [\%] & Adaptability [\%] & Resilience [\%] \\
\hline Flyover intersection & 42 & 56 & 46 & 48 \\
\hline Expressway 11 & 45 & 47 & 46 & 46 \\
\hline D1 Motorway & 51 & 54 & 70 & 58 \\
\hline High-speed railway corridor & 60 & 53 & 70 & 61 \\
\hline Integrated Rescue System & 80 & 79 & 90 & 83 \\
\hline
\end{tabular}

Table 8. Calculated risk level of the spread of cascading impacts

\begin{tabular}{|c|c|c|c|c|}
\hline No & Evaluated Elements & Resilience level [\%] & Link intensity [\%] & Risk level of the spread of cascading impacts [\%] \\
\hline \multirow{2}{*}{1} & Flyover intersection & 48 & \multirow{2}{*}{87} & \multirow{2}{*}{63} \\
\hline & Expressway 11 & 46 & & \\
\hline \multirow{2}{*}{2} & Flyover intersection & 48 & \multirow{2}{*}{63} & \multirow{2}{*}{52} \\
\hline & D1 Motorway & 58 & & \\
\hline \multirow{2}{*}{3} & Flyover intersection & 48 & \multirow{2}{*}{60} & \multirow{2}{*}{50} \\
\hline & High-speed railway corridor & 61 & & \\
\hline \multirow{2}{*}{4} & Expressway 11 & 46 & \multirow{2}{*}{73} & \multirow{2}{*}{41} \\
\hline & Integrated rescue system & 83 & & \\
\hline
\end{tabular}


From the above, it can be concluded that the flyover intersection is an important element of road infrastructure but not considered critical. If the functioning of the flyover failed, the functioning of two road infrastructure elements (i.e., Expressway 11, D1 Motorway) and one rail infrastructure element (i.e., high-speed railway corridor) would also fail.

\section{Discussion}

In the previous section, the ICERI method was introduced. This method permits critical elements of road infrastructure to be identified through CIA. An example of practical application of the proposed method was presented as a case study. A case study applying the ICERI method was demonstrated on the real scenario of the City of Ostrava. The results of the assessment showed that the greatest risk of cascading impacts spreading was from the flyover intersection and Expressway 11. This risk value reached $63 \%$. A situation in the spring of 2019 confirms this assessment: functioning of this flyover intersection was temporarily restricted due to repairs. As a result, traffic on Expressway 11 (i.e. the dependent element) was reduced to only a third of its usual intensity, while traffic on the detour routes doubled, resulting in traffic congestion at peak times.

This section of the article discusses the benefits and added value of the proposed ICERI method compared to existing tools and methods. For this purpose, eight tools and methods were selected, all of which focus on assessing criticality in road transport and whose approaches are nearest in character to the proposed ICERI method:

- network robustness index (Scott et al. 2006);

- method for diagnosis of critical locations in transport infrastructure systems (Taylor, D’Este 2007);

- determining critical links in a road network: vulnerability and congestion indicators (Oliveira et al. 2014);

- method of searching for critical links in traffic network based on link redundancy (Yu et al. 2014);

- practical method for the calculation of link importance (Rupi et al. 2015);

- partial network scan algorithm (Yang et al. 2016);

- methodology for identification of critical infrastructure objects in transport (Dvoŕák et al. 2017);

- identification model of urban critical links with macroscopic fundamental diagram theory (Dong et al. 2017).

The tools and methods listed above were compared using a set of criteria reflecting the defined evaluation conditions, i.e. ICERI. For this purpose, the following criteria were established for comparison: (1) evaluation procedure methodology, (2) topological area of evaluation, (3) typological area of evaluation, (4) criterial area of evaluation, (5) integrated areas of evaluation, (6) consideration of impact intensity, (7) required software support. The comparative analysis of the selected tools and methods according to these criteria examined the clarity, time constraints, feasibility and practical applicability of these tools and methods. The results of the comparative analysis are presented in Table 9.

From the results of the comparative analysis, the current methods clearly only make it possible to mainly assess the criticality of linear elements. Furthermore, these assessments do not consider the systemic links of these elements to dependent or influenced elements in other sectors or sub-sectors. For this reason, they are not useful for comprehensive assessments of critical elements. The results of their application cannot be used by crisis managers to plan potential detour routes. Another undesirable aspect of these methods is their time-consuming and complicated implementation, which does not facilitate workable resolutions to unexpected crisis situations. The proposed ICERI method therefore successfully fills the research gap in the methodology for assessing the criticality of road infrastructure elements. The method is comprehensible, easy to implement, time-saving and systematically evaluates the infrastructure elements of all topological structures.

In the context of the above, this article is primarily aimed at the owners and operators of road infrastructure elements, namely crisis managers. The assessment results can be used to identify critical elements and also to adopt effective security measures aimed at enhancing the resilience of these elements. These results can also be used as input data for modelling, simulation and information systems in crisis management (Ristvej et al. 2013) in order to enhance the resilience of dependent elements, for example, when planning detour routes (Rehak et al. 2019b).

\section{Conclusions}

The article introduced the newly created ICERI method. This method permits the critical elements of road infrastructure to be identified by evaluating cascading impacts and analysing the spread of these impacts in the event of disruption to or failure of these elements. The method is based on assessing the level of resilience and link intensity between correlative elements. The advantages of this method are comprehensibility, feasibility, low demands on time, and importantly, systematically being able to evaluate the infrastructure elements of all topological structures. Impacts can therefore be monitored not only in the road transport sub-sector but across the entire critical infrastructure system. It is also worth noting that the ICERI method can also be used to assess critical elements in railway infrastructure.

Objective identification of critical elements in road infrastructure permits weak areas to be identified early and safety measures aimed at strengthening the resilience of these elements to be effectively adopted. Cyclic application of the ICERI method not only offers continuous assessment of critical elements but also feedback on already implemented safety measures and new risks. For this reason, the method is designed primarily for road infrastructure owners and operators (e.g., Czech Road and Motorway Directorate). Secondary user groups could comprise other 


\begin{tabular}{|c|c|c|c|c|c|c|c|c|c|}
\hline 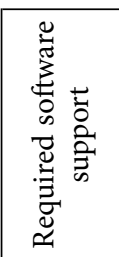 & 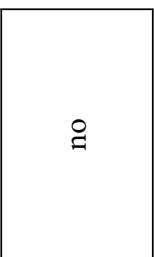 & 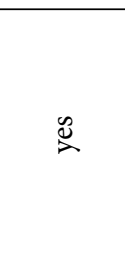 & $\stackrel{\mathscr{Z}}{2}$ & 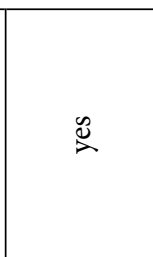 & 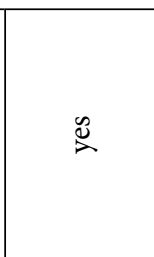 & 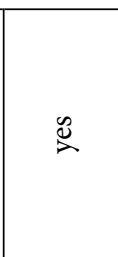 & 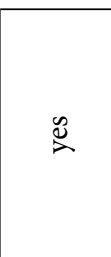 & $\stackrel{9}{9}$ & $\stackrel{\varpi}{\check{\nu}}$ \\
\hline 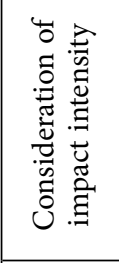 & 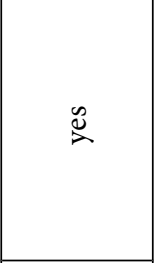 & ‡ & 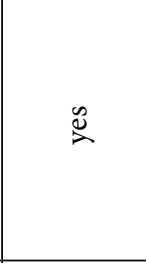 & 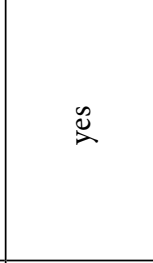 & $\stackrel{9}{\sharp}$ & $\stackrel{9}{9}$ & ‡ & 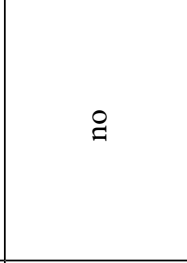 & \& \\
\hline 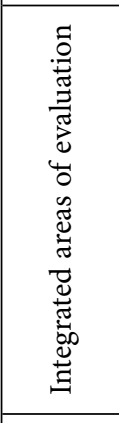 & 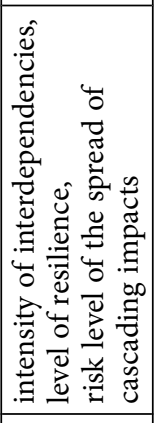 & 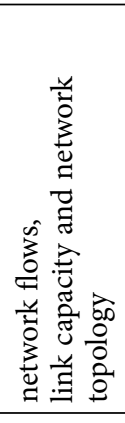 & 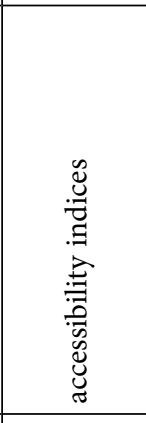 & 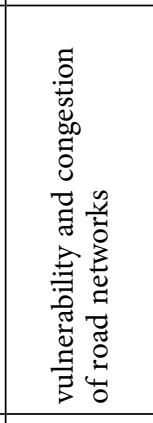 & 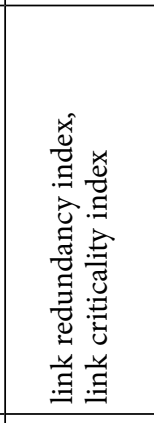 & 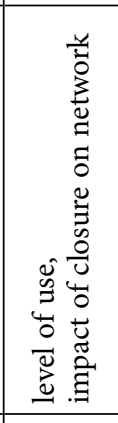 & 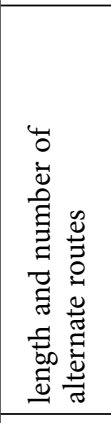 & 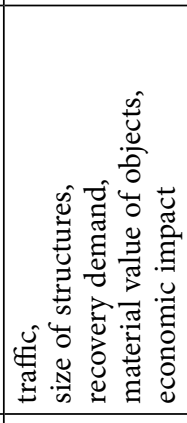 & 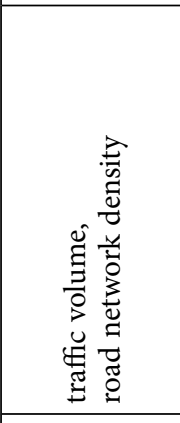 \\
\hline 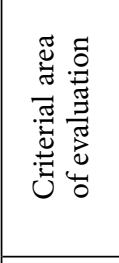 & 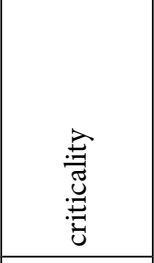 & $\stackrel{\oiiint}{\Xi}$ & 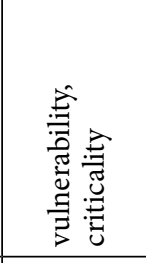 & 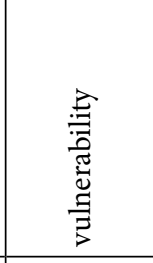 & 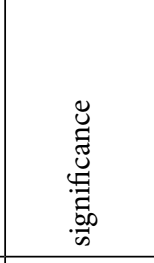 & 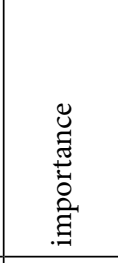 & 栉 & 栉 & 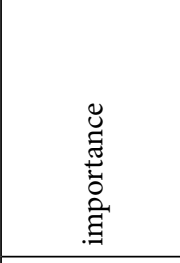 \\
\hline 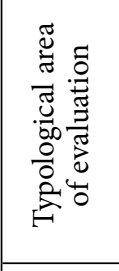 & 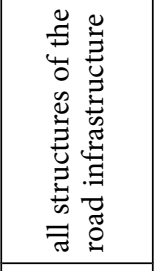 & 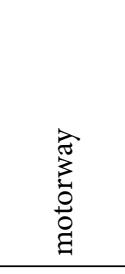 & 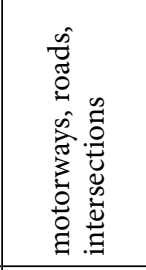 & 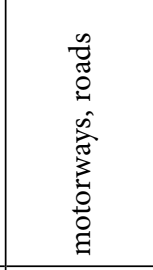 & 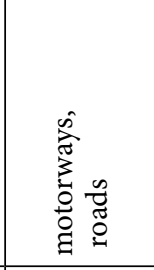 & 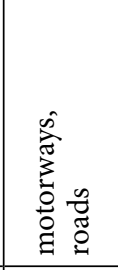 & 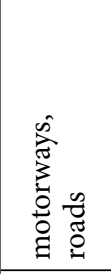 & 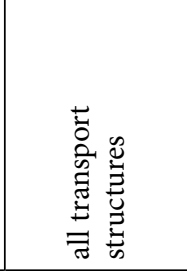 & 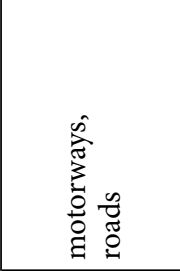 \\
\hline 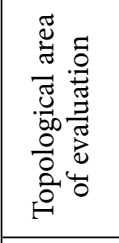 & 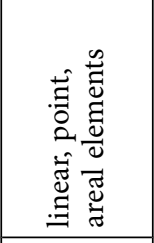 & 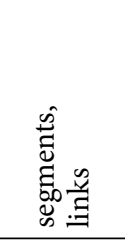 & 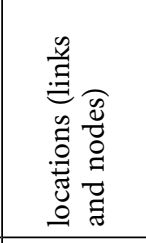 & 畨 & 畨 & 㐘 & 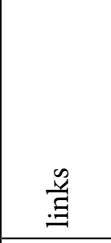 & 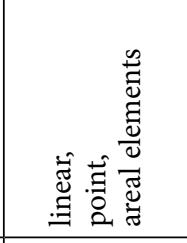 & 㐘 \\
\hline 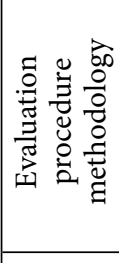 & 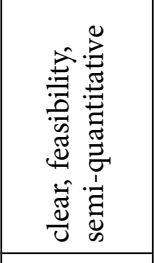 & 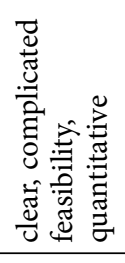 & 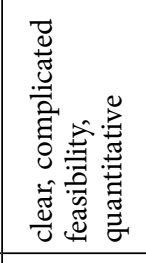 & 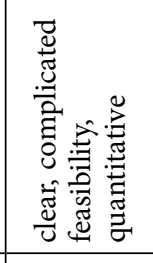 & 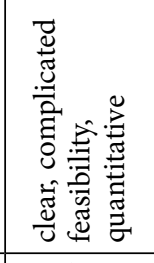 & 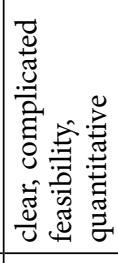 & 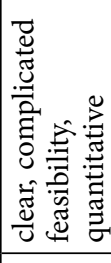 & 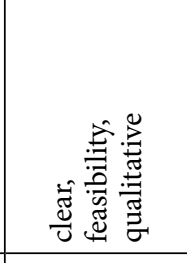 & 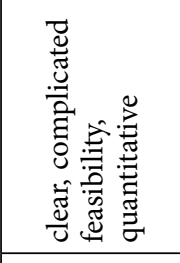 \\
\hline 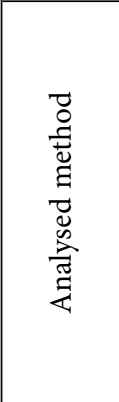 & 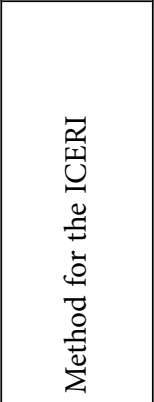 & 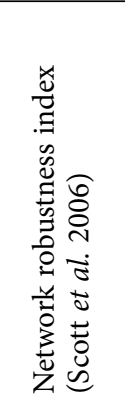 & 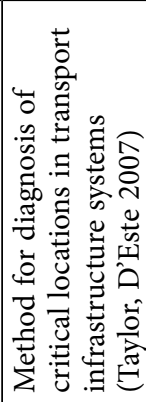 & 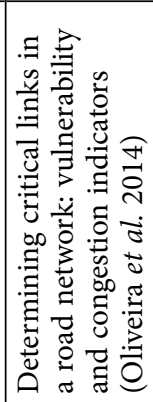 & 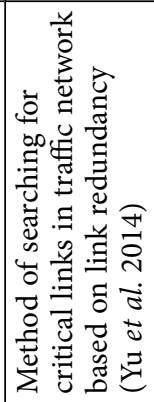 & 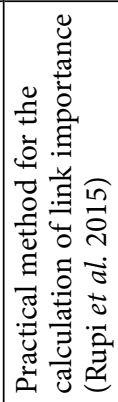 & 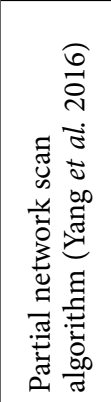 & 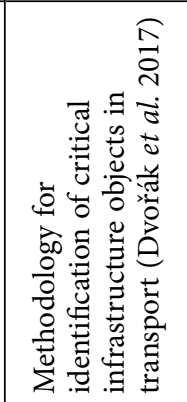 & 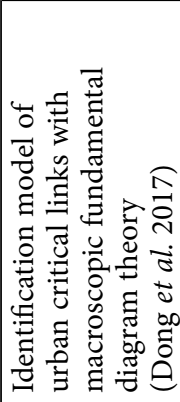 \\
\hline
\end{tabular}


stakeholders, such as road transport coordinators (e.g., Ministry of Transport of the Czech Republic), owners or operators of the infrastructures concerned (e.g., Czech Railway and Traffic Route Administration) or local authorities (e.g., regional or municipal authorities).

\section{Funding}

This work was supported by the Ministry of the Interior of the Czech Republic (Grant No VI20152019049) and the VSB - Technical University of Ostrava (Grant No SP2020/40).

\section{Author contributions}

Conceptualization: David Rehak. Methodology: David Rehak and Veronika Brabcová. Validation: David Rehak, David Patrman, Veronika

Brabcová and Zdeněk Dvořák. Investigation: David Rehak and David Patrman. Writing - original draft preparation: David Rehak and Zdeněk Dvořák Visualization: David Rehak. Supervision: David Rehak. Project administration: David Rehak. Funding acquisition: David Rehak.

\section{Disclosure statement}

No potential conflict of interest was reported by the authors.

\section{References}

Ambros, J.; Turek, R.; Brich, M.; Kubeček, J. 2019. Safety assessment of Czech motorways and national roads, European Transport Research Review 11: 1.

https://doi.org/10.1186/s12544-018-0328-2

Bertocchi, G.; Bologna, S.; Carducci, G.; Carrozzi, L.; Cavallini, S.; Lazari, A.; Oliva, G.; Traballesi, A. 2016. Guidelines for Critical Infrastructures Resilience Evaluation. Italian Association of Critical Infrastructures Experts (AIIC). 101 p. Available from Internet: http://www.infrastrutturecritiche. it/new/media-files/2016/04/Guidelines_Critical_Infrastructures_Resilience_Evaluation.pdf

Bie, W.; Wang, X. 2002. Evaluation of power system cascading outages, in Proceedings. International Conference on Power System Technology, 13-17 October 2002, Kunming, China, 415-419. https://doi.org/10.1109/ICPST.2002.1053577

Chen, B. Y.; Lam, W. H. K.; Sumalee, A.; Li, Q.; Li, Z.-C. 2012. Vulnerability analysis for large-scale and congested road networks with demand uncertainty, Transportation Research Part A: Policy and Practice 46(3): 501-516.

https://doi.org/10.1016/j.tra.2011.11.018

Chen, Y.; Milanović, J. V. 2017. Critical appraisal of tools and methodologies for studies of cascading failures in coupled critical infrastructure systems, in IEEE EUROCON 2017: 17th International Conference on Smart Technologies, 6-8 July 2017, Ohrid, Macedonia, 599-604.

https://doi.org/10.1109/EUROCON.2017.8011182
David, H. A. 1988. The Method of Paired Comparisons. Hodder Arnold. 200 p.

Dong, W.; Wang, Y.; Yu, H. 2017. An identification model of urban critical links with macroscopic fundamental diagram theory, Frontiers of Computer Science 11(1): 27-37. https://doi.org/10.1007/s11704-016-6080-7

Dvořák, Z.; Sventeková, E.; Řehák, D.; Čekerevac, Z. 2017. Assessment of critical infrastructure elements in transport, Procedia Engineering 187: 548-555. https://doi.org/10.1016/j.proeng.2017.04.413

EC. 2008. Council Directive 2008/114/EC of 8 December 2008 on the Identification and Designation of European Critical Infrastructures and the Assessment of the Need to Improve their Protection. Available from Internet: http://data.europa.eu/eli/dir/2008/114/oj

EC. 2006. Commission Regulation (EC) No 851/2006 of 9 June 2006 Specifying the Items to be Included under the Various Headings in the Forms of Accounts Shown in Annex I to Council Regulation (EEC) No 1108/70. Available from Internet: http://data.europa.eu/eli/reg/2006/851/oj

Eurostat. 2018. Road Freight Transport Statistics - Cabotage. Statistical Office of the European Union (Eurostat). Available from Internet: https://ec.europa.eu/eurostat/statisticsexplained/index.php/Road_freight_transport_statistics_-_ cabotage

Giannopoulos, G.; Filippini, R.; Schimmer, M. 2012. Risk assessment methodologies for Critical Infrastructure Protection. Part I: A state of the Art. Joint Research Centre (JRC), European Commission. 53 p. https://doi.org/10.2788/22260

Gonzva, M.; Barroca, B.; Gautier, P.-E.; Diab, Y. 2016. Analysis of disruptions cascade effect within and between urban sociotechnical systems in a context of risks, E3S Web of Conferences 7: 07008. https://doi.org/10.1051/e3sconf/20160707008

Hassel, H.; Johansson, J.; Cedergren, A.; Svegrup, L.; Arvidsson, B. 2014. Method to Study Cascading Effects. CascEff Project: Deliverable No D2.1. Lund University, Sweden. 40 p. Available from Internet: http://casceff.eu/media2/2016/02/D2.1-Deliverable_Final_Ver2_PU.pdf

Hromada, M.; Lukas, L. 2012. Multicriterial evaluation of critical infrastructure element protection in Czech Republic, Communications in Computer and Information Science 340: 361368. https://doi.org/10.1007/978-3-642-35267-6_48

IEC 60812:2006. Analysis Techniques for System Reliability - Procedure for Failure Mode and Effects Analysis (FMEA).

IEC 61025:2006. Fault Tree Analysis (FTA).

IEC 62502:2010. Analysis Techniques for Dependability - Event Tree Analysis (ETA).

IEC 31010:2019. Risk Management - Risk Assessment Techniques.

IRDR. 2014. Peril Classification and Hazard Glossary. Data Project Report No 1. Integrated Research on Disaster Risk (IRDR), Beijing, China. 28 p. Available from Internet: http://www.irdrinternational.org/2014/03/28/irdr-peril-classification-and-hazard-glossary

Jenelius, E. 2007. Approaches to Road Network Vulnerability Analysis. Department of Transport and Economics, Royal Institute of Technology (KTH), Stockholm, Sweden. 29 p.

Jenelius, E.; Petersen, T.; Mattsson, L.-G. 2006. Importance and exposure in road network vulnerability analysis, Transportation Research Part A: Policy and Practice 40(7): 537-560. https://doi.org/10.1016/j.tra.2005.11.003

Klein, P.; Hutter, R. 2017. Qualitative criteria in the assessment of security measures for critical infrastructure protection - a new approach, International Journal of Critical Infrastructures 13(1): 29-45. https://doi.org/10.1504/IJCIS.2017.083637 
Kotzanikolaou, P.; Theoharidou, M.; Gritzalis, D. 2013. Cascading effects of common-cause failures in critical infrastructures, IFIP Advances in Information and Communication Technology 417: 171-182. https://doi.org/10.1007/978-3-642-45330-4_12

Labaka, L.; Hernantes, J.; Sarriegi, J. M. 2015. A framework to improve the resilience of critical infrastructures, International Journal of Disaster Resilience in the Built Environment 6(4): 409-423. https://doi.org/10.1108/IJDRBE-07-2014-0048

Leitner, B.; Decký, M.; Kováč, M. 2019. Road pavement longitudinal evenness quantification as stationary stochastic process, Transport 34(2): 195-203.

https://doi.org/10.3846/transport.2019.8577

Leitner, B.; Môcová, L.; Hromada, M. 2017. A New approach to identification of critical elements in railway infrastructure, Procedia Engineering 187: 143-149.

https://doi.org/10.1016/j.proeng.2017.04.360

Leitner, B.; Rehak, D.; Keršys, R. 2018. The new procedure for identification of infrastructure elements significance in subsector railway transport, Komunikácie / Communications 20(2): 41-48.

Liao, H.; Apt, J.; Talukdar, S. 2004. Phase Transitions in the Probability of Cascading Failures. Working Paper. Carnegie Mellon University, Pittsburgh, PA, US. 4 p. Available from Internet: https://www.cmu.edu/ceic/assets/docs/publications/workingpapers/ceic-04-08.pdf

Min, H.-S. J.; Beyeler, W.; Brown, T.; Son, Y. J.; Jones, A. T. 2007. Toward modeling and simulation of critical national infrastructure interdependencies, IIE Transactions 39(1): 57-71. https://doi.org/10.1080/07408170600940005

Nan, C.; Sansavini, G. 2017. A quantitative method for assessing resilience of interdependent infrastructures, Reliability Engineering \& System Safety 157: 35-53. https://doi.org/10.1016/j.ress.2016.08.013

NIAC. 2009. National Infrastructure Advisory Council Critical Infrastructure Resilience: Final Report and Recommendations. National Infrastructure Advisory Council (NIAC), US Department of Homeland Security, Washington, DC, US. 54 p. Available from Internet: https://www.cisa.gov/publication/ niac-critical-infrastructure-resilience-final-report

Oliveira, E. L.; Portugal, L. da S.; Porto Junior, W. 2014. Determining critical links in a road network: vulnerability and congestion indicators, Procedia - Social and Behavioral Sciences 162: 158-167. https://doi.org/10.1016/j.sbspro.2014.12.196

Pant, R.; Hall, J. W.; Blainey, S. P. 2016. Vulnerability assessment framework for interdependent critical infrastructures: casestudy for Great Britain's rail network, European Journal of Transport and Infrastructure Research 16(1): 174-194. https://doi.org/10.18757/ejtir.2016.16.1.3120

Patrman, D.; Splichalova, A.; Rehak, D.; Onderkova, V. 2019. Factors influencing the performance of critical land transport infrastructure elements, Transportation Research Procedia 40: 1518-1524. https://doi.org/10.1016/j.trpro.2019.07.210

Public Safety Canada. 2018. National Cross Sector Forum: 20182020 Action Plan for Critical Infrastructure. Public Safety Canada, Ottawa, Canada. 25 p. Available from Internet: https://www.publicsafety.gc.ca/cnt/rsrcs/pblctns/pln-crtclnfrstrctr-2018-20

Rehak, D.; Markuci, J.; Hromada, M.; Barcova, K. 2016. Quantitative evaluation of the synergistic effects of failures in a critical infrastructure system, International Journal of Critical Infrastructure Protection 14: 3-17.

https://doi.org/10.1016/j.ijcip.2016.06.002
Rehak, D.; Novotny, P. 2016. Bases for modelling the impacts of the critical infrastructure failure, Chemical Engineering Transactions 53: 91-96. https://doi.org/10.3303/CET1653016

Rehak, D.; Senovsky, P.; Hromada, M.; Lovecek, T.; Novotny, P. 2018. Cascading impact assessment in a critical infrastructure system, International Journal of Critical Infrastructure Protection 22: 125-138. https://doi.org/10.1016/j.ijcip.2018.06.004

Rehak, D.; Senovsky, P.; Hromada, M.; Lovecek, T. 2019a. Complex approach to assessing resilience of critical infrastructure elements, International Journal of Critical Infrastructure Protection 25: 125-138. https://doi.org/10.1016/j.ijcip.2019.03.003

Rehak, D.; Radimsky, M.; Hromada, M.; Dvorak, Z. 2019b. Dynamic impact modeling as a road transport crisis management support tool, Administrative Sciences 9(2): 29. https://doi.org/10.3390/admsci9020029

Renger, R.; Foltysova, J.; Ienuso, S.; Renger, J.; Booze, W. 2017. Evaluating system cascading failures, Evaluation Journal of Australasia 17(2): 29-36. https://doi.org/10.1177/1035719X1701700205

Rinaldi, S. M.; Peerenboom, J. P.; Kelly, T. K. 2001. Identifying, understanding, and analyzing critical infrastructure interdependencies, IEEE Control Systems Magazine 21(6): 11-25. https://doi.org/10.1109/37.969131

Ristvej, J.; Zagorecki, A.; Hollá, K.; Šimák, L.; Titko, M. 2013. Modelling, simulation and information systems as a tool to support decision making process in crisis management, in 27th European Simulation and Modelling Conference ESM'2013, 23-25 October 2013, Lancaster, UK, 71-76.

RSD. 2012. Zvlněná dálnice u Ostravy má rekordních 901 vad. Ředitelství silnic a dálnic (RSD) ČR. Česká Republika. Available from Internet: https://www.rsd.cz (in Czech).

Rupi, F; Angelini, S.; Bernardi, S.; Danesi, A.; Rossi, G. 2015. Ranking links in a road transport network: a practical method for the calculation of link importance, Transportation Research Procedia 5: 221-232.

https://doi.org/10.1016/j.trpro.2015.01.003

Scott, D. M.; Novak, D. C.; Aultman-Hall, L.; Guo, F. 2006. Network robustness index: a new method for identifying critical links and evaluating the performance of transportation networks, Journal of Transport Geography 14(3): 215-227. https://doi.org/10.1016/j.jtrangeo.2005.10.003

Seppänen, H.; Luokkala, P.; Zhang, Z.; Torkki, P.; Virrantaus, K. 2018. Critical infrastructure vulnerability - a method for identifying the infrastructure service failure interdependencies, International Journal of Critical Infrastructure Protection 22: 25-38. https://doi.org/10.1016/j.ijcip.2018.05.002

Slivková, S. 2018. Určování kritických prvků v oblasti železniční dopravy. Disertační práce pro získání akademického titulu „doktor“, ve zkratce „Ph.D.“. Technická univerzita Ostrava, Česká republika. 123 s. (in Czech). Available from Internet: https://dspace.vsb.cz/bitstream/handle/10084/133108/ SLI0006_FBI_P3908_3908V009_2018.pdf

Slivkova, S.; Rehak, D.; Novotny, P. 2018. Critical element designation system in rail transport in the Czech Republic, Chemical Engineering Transactions 67: 775-780. https://doi.org/10.3303/CET1867130

Slivková, S.; Tašlová, J.; Novotný, P. 2015. Návrh kritérií kritičnosti prvků železniční dopravní infrastruktury, in Požární ochrana 2015: Sborník přednášek XXIV. ročníku mezinárodní konference, 9.-10. záŕí 2015, Ostrava, Česká Republika, 3: 291-294. (in Czech). 
Štoller, J.; Dvořák, P.; Túró, T.; Zezulová, E. 2018. Basic principles of critical infrastructure protection, in Transport Means 2018: Proceedings of the 22nd International Scientific Conference, 3-5 October 2018, Kaunas, Lithuania, 1: 267-271.

Taylor, M. A. P.; D'Este, G. M. 2007. Transport network vulnerability: a method for diagnosis of critical locations in transport infrastructure systems, in A. T. Murray, T. H. Grubesic (Eds.). Critical Infrastructure. Advances in Spatial Science, 9-30. https://doi.org/10.1007/978-3-540-68056-7_2

Taylor, M. A. P.; Sekhar, S. V. C.; D’Este, G. M. 2006. Application of accessibility based methods for vulnerability analysis of strategic road networks, Networks \& Spatial Economics 6(3-4): 267-291. https://doi.org/10.1007/s11067-006-9284-9

The White House. 2013. Critical Infrastructure Security and Resilience. Presidential Policy Directive PPD-21. The White House, Washington, DC, US. Available from Internet: https:// obamawhitehouse.archives.gov/the-press-office/2013/02/12/ presidential-policy-directive-critical-infrastructure-securityand-resil

UNECE. 2018. 2018 Inland Transport Statistics for Europe and North America. Volume LIX. United Nations Economic Commission for Europe (UNECE). 189 p. Available from Internet: https://www.unece.org/fileadmin/DAM/trans/main/wp6/publications/2018_INLAND_TRANSPORT_STATISTICS.pdf

Weihrich, H. 1982. The TOWS matrix - a tool for situational analysis, Long Range Planning 15(2): 54-66. https://doi.org/10.1016/0024-6301(82)90120-0

Yang, X.; Liu, L.; Li, Y.; He, R. 2016. Identifying critical links in urban traffic networks: a partial network scan algorithm, Kybernetes 45(6): 915-930. https://doi.org/10.1108/K-05-2015-0144

Yu, C.; Yang, X.; Yun, M. 2014. Method of Searching for Critical Links in Traffic Network Based on Link Redundancy, in Transportation Research Board 93rd Annual Meeting, 12-16 January 2014, Washington, DC, US, 1-17.

Zimmerman, R.; Restrepo, C. E. 2009. Analyzing cascading effects within infrastructure sectors for consequence reduction, in 2009 IEEE Conference on Technologies for Homeland Security, 11-12 May 2009, Boston, MA, US 165-170. https://doi.org/10.1109/THS.2009.5168029

Zuccaro, G.; De Gregorio, D.; Leone, M. F. 2018. Theoretical model for cascading effects analyses, International Journal of Disaster Risk Reduction 30: 199-215.

https://doi.org/10.1016/j.ijdrr.2018.04.019 